\title{
NOMBRES BOTANICOS DE ALGUNAS PLANTAS DE TEPOZTLAN, MOR.
}

\author{
Por el Dr. B. P. Reko.
}

Acháyatl (Jarilla) - Senecio salignus D. C.-Atl, agua o cerca del agua; chachayua, caer poco a poco o esparcirse por el suelo, aludiendo a los aquenios voladores.

Clemole (mol-xóchitl) - Tagetes patula L.- Tletl,, fuego o color de fuego; moloni, levantarse con el viento las plumas (aquenios con vilanos) Flecos de color de fuego.

Chilpil-xóchitl (chespiche)-Crotalaria sp. -Chepille, cosa inflada o vaina inflada; xóchitl, flor.

Cocozatona (cinco llagas) - Tagetes lunulata Ort.-_Cocoztic, amarillo; tontli, chaparro o pequeño.

Mich-patli - Buddleia verticillata H. B. K.-Tal vez de miztli, gato; patli, remedio.

Mol-xóchitl (clemole) - Tagetes patula L.—Moloni, fleco gavilán; xóchitl; flor. Patla-xoxohui (lengua de vaca) - Buddleia verticillata H. B. K.-Patla, desha cerse, desvaido, xoxohui, verde. Alude al color desvaído de las hojas.

Paztlapozo - Tournerfortia sp.

Pilipil-xihuitl (pipilolxóchitl) — Lobelia laxiflora H. B. K.-Pipilolli, cosa colgada; xóchitl, flor; xihuitl, hierba: de la flor colgada.

Temix-tapextli-Alternanthera repens (L) Kuntze.- Temixihuiztli, pasto; topeua, empujar.

Tonalcotl-xihuitl - Dodonae viscosa Jacq.-Tonalocoltl, pino de sol; xihuitl, hierba. Es el Tonal-ocotl de Hernández. Arbusto de hojas viscosas, que mana resina como un ocote.

Tlequáhuitl (mamalhuaztli) - Cletra lanata Mart. \&. Gal.- Tletl, fuego; quáhuitl, arbol árbol de fuego. Mamalhuaztli son las astillas para producir fuego, y es también el nombre de una constelación (alpha, beta, gama Arietis) cerca de Las Cabrillas (Pléyades), de acuerdo con Sahagún. 
Tzotzon-iztalli - Piqueria trinervia Cav.-Tzo-tzone, cosa que tiene cabellos iztac, blanco: cabellos blancos. Alude a los capítulos con aquenios blancos.

Zoapatli - Montanoa floribunda (H. B. K.) Shultz.-Zohuatl, cihuatl, mujer; patli, remedio: remedio para el parto.

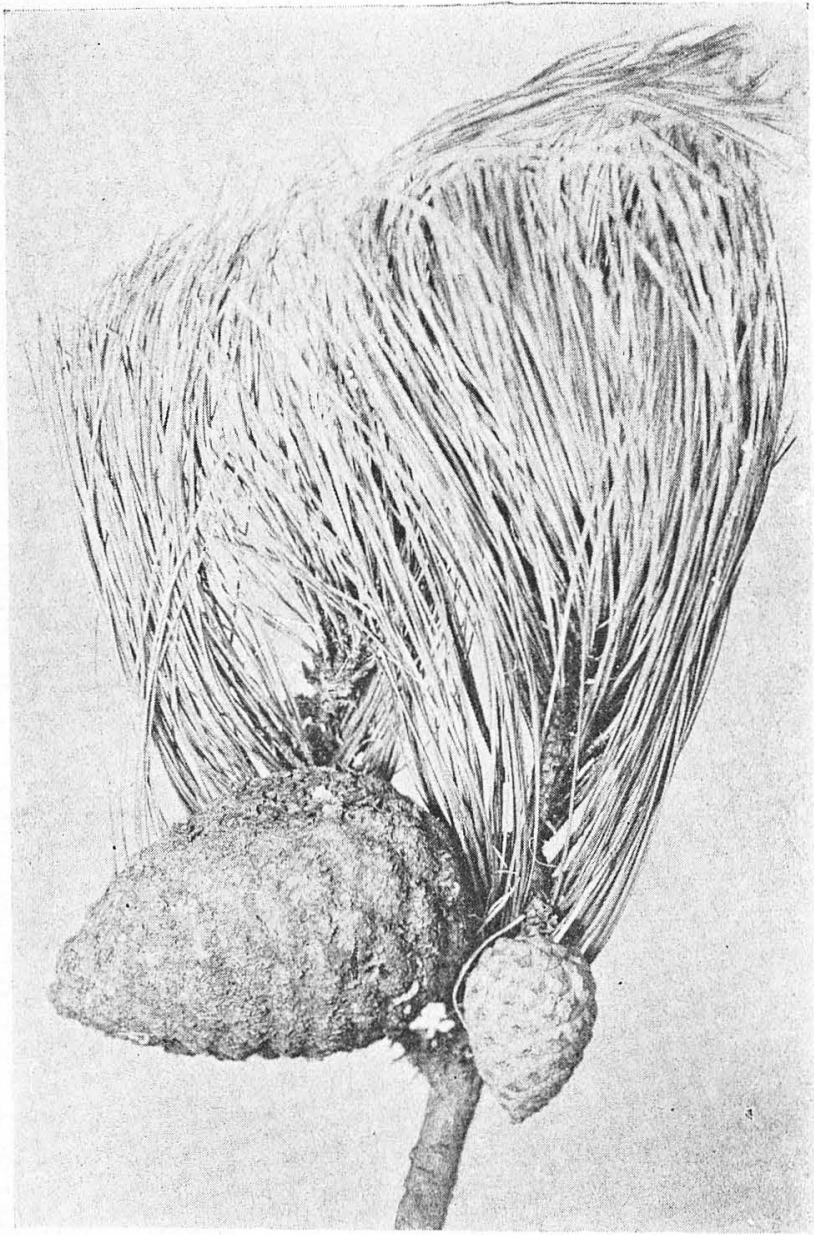

Pinus oocarpa mostrando un cono normal y otro hipertrofiado por el ataque de un hongo (Caeoma conigenum,) 